\title{
Correlation between Chemical Characterization and Biological Activity: An Urgent Need for Human Studies Using Extra Virgin Olive Oil
}

\author{
Stefania De Santis ${ }^{1, * \mathbb{D}}$, Maria Lisa Clodoveo ${ }^{2}$ id and Filomena Corbo $^{1}$ (D) \\ 1 Department of Pharmacy-Pharmaceutical Science, University of Bari Aldo Moro, 70126 Bari, Italy; \\ filomena.corbo@uniba.it \\ 2 Department of Interdisciplinary Medicine, University of Bari Aldo Moro, 70124 Bari, Italy; \\ marialisa.clodoveo@uniba.it \\ * Correspondence: stefania.desantis@uniba.it; Tel.: +39-080-544-2763
}

check for updates

Citation: De Santis, S.; Clodoveo,

M.L.; Corbo, F. Correlation between Chemical Characterization and Biological Activity: An Urgent Need for Human Studies Using Extra

Virgin Olive Oil. Antioxidants 2022,

11, 258. https://doi.org/10.3390/

antiox11020258

Academic Editors: Catalina

Alarcòn de-la-Lastra and

Stanley Omaye

Received: 27 December 2021

Accepted: 27 January 2022

Published: 28 January 2022

Publisher's Note: MDPI stays neutral with regard to jurisdictional claims in published maps and institutional affiliations.

Copyright: (c) 2022 by the authors. Licensee MDPI, Basel, Switzerland. This article is an open access article distributed under the terms and conditions of the Creative Commons Attribution (CC BY) license (https:/ / creativecommons.org/licenses/by/ $4.0 /)$.

\begin{abstract}
Extra virgin olive oil (EVOO) is one of the most important functional foods from the Mediterranean Diet due to its beneficial effect on human health in terms of prevention and/or adjuvant treatment of different pathological conditions. The positive effects linked to EVOO consumption are not only due to its major (monounsaturated fatty acids), but also to its minor components (phenolics), whose roles were greatly re-evaluated in the last years. Notwithstanding the huge number of studies demonstrating the antioxidant, anti-inflammatory and anti-cancer properties of EVOO's phenolic compounds, only their antioxidant ability was supported by a Health Claim. However, to bear the claim, a specific phenolic composition is needed, thus reinforcing the need to correlate the characterization of the phenolic compounds to their biological activity. In fact, although the chemical characterization of VOO's phenolic compounds was extensively studied, its correlation with biological effects is only partially investigated; this is especially true for human studies. This review aims to study the correlation between the chemical characterization of EVOO's phenolics and the biological effects in terms of antioxidant/anti-inflammatory potentials, with a focus on the human studies and the relative concern on getting a specific Health Claim.
\end{abstract}

Keywords: extra virgin olive oil; polyphenols; chemical characterization; antioxidant activity; anti-inflammatory potential; human studies; health claim

\section{Introduction}

Extra virgin olive oil (EVOO) is one of the most important functional foods from the Mediterranean Diet (MD) and its consumption is linked to a reduction in the risk of cardiovascular and chronic inflammatory diseases [1-4]. The beneficial effect of olive oil on human health depends on the high content of both the monounsaturated fatty acids (MUFAs) (80\% of its total lipid composition) and the phenolic compounds, polar molecules, whose extremely variable concentration is a function of agronomic and technological conditions [5-8]. Even if present at a low extent (1-2\% of EVOO), the phenolic compounds were re-evaluated in recent last years, as indicated by the huge number of papers demonstrating their efficacy in the prevention and/or as adjuvant treatment for different pathological conditions thanks to the antioxidant, anti-inflammatory and anti-cancer properties [9-11]. Importantly, some of these papers were considered for the establishment of a specific Health Claim by the EFSA (European Food Safety Authority). Notwithstanding the multitude of studies underlying the anti-inflammatory and anti-cancer properties of the phenolic compounds, only the antioxidant ability is fully established for these compounds, even if a specific chemical composition is required (see below). This requirement reinforces the need to correlate the characterization of the phenolic compounds to their biological activity; this is especially true for human studies, even if this correlation is often missing in these 
cases. In fact, although the chemical characterization of VOO's phenolic compounds was extensively studied with consolidated techniques $[12,13]$, its correlation with the biological effects, mainly linked to the antioxidant and/or the anti-inflammatory properties, is only partially investigated.

The aim of this review is to examine the state-of-art of the human studies in which a detailed chemical characterization of polyphenols from EVOO/VOO (only administered in the raw form) was correlated to the biological effects in terms of antioxidant and antiinflammatory potentials.

\section{Correlation among EVOO Polyphenols Chemical Characterization, Antioxidant Activity and Biological Effects in Human Studies}

The antioxidant activity of VOO's polyphenols was studied in different pathological contexts. One of the most investigated contexts of VOO's biological activities in humans is cardiovascular disease (CVD) prevention, that relies on different mechanisms, such as the improvement of the lipid profile by increasing high density lipoprotein (HDL)-cholesterol and reducing low density lipoprotein (LDL)-cholesterol and triglycerides (TAG) [14], the reduction of oxidative stress, and the inhibition of human lipoprotein oxidation [15]. On this basis, EFSA approved a Health Claim on 2011 establishing a cause-effect relationship between the consumption of olive oil polyphenols (standardized by the content of hydroxytyrosol and its derivatives) and the protection of LDL particles from the oxidative damage. To bear this claim, $\mathrm{OO}$ has to contain $5 \mathrm{mg}$ of hydroxytyrosol and its derivatives (e.g., oleuropein complex and tyrosol) per $20 \mathrm{~g}$ of $\mathrm{OO}$ [16]. This Health Claim was accepted by the European Union (EU) one year later [17]. One of the most well-structured studies taken into account by the EFSA Panel for this Health Claim is the EUROLIVE study, a randomized, cross-over, controlled intervention trial in which 200 healthy subjects were enrolled for a sustained consumption of VOO with high $(366 \mathrm{mg} / \mathrm{kg})$, moderate $(164 \mathrm{mg} / \mathrm{kg})$ and low $(2.7 \mathrm{mg} / \mathrm{kg}$ ) polyphenols content (HPC, MPC and LPC, respectively) [15]. The authors observed a dose-dependent effect between the increase of polyphenols content in VOO and the decrease in LDL peroxidation, conjugated dienes and hydroxy fatty acids, and an increase in HDL-cholesterol concentrations. As reported before, the maintenance of normal blood HDL-cholesterol concentrations is another beneficial effect evaluated by the EFSA Panel for the substantiation of the Health Claim on OO polyphenols. However, until now there has been no sufficient evidence supporting this effect, thus the studies analyzed were considered inconsistent. Moreover, in this trial, as well as in other trials discussed later [18-24], an important application of the chemical techniques is their use to test the dietary adherence, thus overcoming the self-reporting bias of food frequency questionnaires or food recalls to the study participants.

Dose-dependent positive feedback in terms of LDL peroxidation reduction was also shown for phenolic compounds in a subpopulation of subjects from the EUROLIVE study [25].

Considering that oxidative stress also supports endothelial dysfunction, a post prandial consumption of HPC (400 mg/ $\mathrm{kg})$ and LPC (80 mg/kg) VOO was administered to hypercholesterolaemic volunteers [26]. Even if, also in this case, the phenolic composition of VOO was not sufficiently chemically characterized, the authors demonstrated the ability of high content of VOO phenolics to revert the impairment of the endothelial function during the post-prandial state. The mechanisms of action included the reduction of the oxidative stress measured as lipoperoxides (LPO) and 8-iso-F2 $\alpha$ levels, and the increase of the nitric oxide (NO) metabolites, as demonstrated by biochemical analyses. However, LPO did not seem to be a reliable marker for lipid peroxidation, and the modulation of F2 $\alpha$-isoprostanes by phenolic content, different to what was found by Widmer et al. [27], but in accordance with other clinical trials [15,18,20], was not significant.

Apart from these clinical trials, Table 1 reports additional human studies correlating the chemical characterization of VOO phenolic compounds in terms of quantity and quality, with the antioxidant and anti-inflammatory (see below) abilities tested by chemical or 
biochemical and cellular assays. However, a list of additional clinical trials using $\mathrm{OO}$ polyphenols, non-restricted to the row form of olive oil and to the correlation with their chemical characterization, is reported by Flori et al. [28].

Concerning the EVOO phenolic antioxidant potential, total polyphenols quantification by the Folin-Ciocalteu and HPLC methods was correlated to the ability to protect against LDL oxidation; this effect correlated with the phenolic concentration of EVOO. Specifically, by an ex vivo study the authors demonstrated that, after incubation with plasma, EVOO phenols could be incorporated into LDL particles and exert their antioxidant activity [30]. The antioxidant ability of EVOO phenolics correlates to the prevention of cardiovascular diseases, as also reported in the PREDIMED study in which human subjects consumed EVOO or nuts in the context of an MD [38].

However, for the ability of VOO polyphenols to bind to LDL, some crucial aspects have to be taken into account when clinical trials were performed, e.g., the analysis of metabolites instead of EVOO primary species and the need to use a highly sensitive detection technique following an adequate extraction procedure in order to minimize the matrix effect. In fact, phenolic compounds undergo an intensive intestinal and hepatic metabolism after ingestion. For this reason, it could be better to consider metabolites instead of the primary species for the study of EVOO biological activity, even if their concentration is very low. Delatorre-Carbot et al. demonstrated that HPLC-ESI-MS/MS determination after solid phase extraction gave the best results in terms of T and HT metabolites quantification on LDL recovered from healthy subjects' plasma after a post prandial administration of EVOO Picual variety of the O. europaea L. fruit [31]. Specifically, hydroxytyrosol monosulfate, hydroxytyrosol monoglucuronide, tyrosol sulfate, tyrosol glucuronide and homovanillic acid sulfate are able to bind to human LDL, reinforcing their antioxidant action in vivo. Another clinical trial investigating the effect of specific metabolites of $\mathrm{OO}$ phenols on human LDL lipid composition and peroxidation was conducted on a subsample population of the EUROLIVE study [32]. Specifically, VOO with HPC significantly increased the concentrations of hydroxytyrosol monosulfate and homovanillic acid sulfate (but not of tyrosol sulfate) in LDL particles and decreased the concentration of circulating markers of lipid peroxidation, including LDL particles (oxLDL), conjugated dienes and hydroxy fatty acids. Thus, an inverse relationship between the degree of LDL peroxidation and the concentrations of phenolic metabolites in LDL particles was observed.

Moreover, many other clinical trials studying the antioxidant potential of VOO phenolic compounds were performed, but only some of them reported a detailed chemical characterization. These trials were performed on healthy subjects and differed for their timing (sustained consumption vs. short-term/acute consumption). In the first case, the protective effect of $\mathrm{VOO}$ with a high polyphenols content was demonstrated on healthy volunteers who had undergone a sustained consumption of refined, common and VOO [19]. The ever-increased phenolic concentration in the three groups (refined $<$ common $<\mathrm{VOO}$ ), as reported by the Folin-Ciocalteau method and HPLC analysis, correlated with a more effective LDL protection from oxidation, as demonstrated by a decrease in oxidized LDL (oxLDL) and an increase of HDL cholesterol levels. In the short-term trial, healthy subjects consumed EVOO with HPC (486 mg/kg), MPC (133 mg/kg) and LPC $(10 \mathrm{mg} / \mathrm{kg})$ for four days [20]. As also recognized by the EFSA panel, a dose-dependent effect was observed between the EVOO polyphenols content with a decrease in LDL peroxidation and malondialdehyde (MDA) and an increase in the antioxidant glutathione peroxidase activity (GSH-Px) [16]. As indicated before, a not significant modulation was reported for 8 -iso-prostaglandin F2 $\alpha$. Finally, an acute intake of HPC (366 mg/kg), MPC (164 mg/kg) and LPC $(2.7 \mathrm{mg} / \mathrm{kg})$ in healthy subjects demonstrated a direct correlation between the content of VOO phenolic compounds and a significant decrease in plasma oxLDL $[16,18]$. In this case, the 8-iso-prostaglandin F2 $\alpha$ measurement did not show a dose-dependent effect relative to phenolic content variation too. 
Table 1. Summary of human studies analyzing the antioxidant and anti-inflammatory properties of EVOO/VOO by a different combination of chemical, biochemical and biological assays, starting from the chemical characterization of the OO phenolic profile. 8-iso-PGF2 $\alpha$ : 8 -epi-isoprostane prostaglandin F2 $\alpha$; ABTS: 2,2'-Azinobis-(3-ethylbenzothiazoline-6-sulfonic acid); ALT: alanine transaminase; AST: aspartate transaminase; CAT: catalase; CRP: C-reactive protein; DPPH: 2,2-diphenyl-1-picrylhydrazyl; ELISA: enzyme-linked immunosorbent assay; EVOO: extra virgin olive oil; FRAP: ferric reducing antioxidant power; GR: GSH reductase activity; GSH: glutathione; GSH-px: GSH peroxidase; $\mathrm{H}_{2} \mathrm{O}_{2}$ : hydrogen peroxide; HDL-C: high density lipoprotein cholesterol; HPC: high polyphenols content; HT: hydroxytyrosol; LDL-C: low density lipoprotein cholesterol; LPC: low polyphenols content; LPO: levels of lipoperoxides; MDA: malondialdehyde; MHT: 3-O-methylhydroxytyrosol; MPC: moderate polyphenols content; NO(x): nitrates/nitrites; OLAB: oxLDL serum antibodies; oxLDL: oxidized LDL; ROO: refined olive oil; SOD: superoxide dismutase; T: tyrosol; T2D: type 2 diabetes mellitus; TAC: total antioxidant capacity; TAG: triglycerides; TAS: total antioxidant status; TBARS: thiobarbituric acid reactive substances assay; VOO: virgin olive oil.

\begin{tabular}{|c|c|c|c|c|c|c|c|}
\hline \multirow{2}{*}{$\begin{array}{l}\text { Sample/ } \\
\text { Treatment }\end{array}$} & \multicolumn{2}{|c|}{$\begin{array}{l}\text { Human } \\
\text { Studies }\end{array}$} & \multicolumn{2}{|c|}{$\begin{array}{l}\text { Antioxidant } \\
\text { Test }\end{array}$} & \multirow{2}{*}{$\begin{array}{l}\text { Anti-Inflammatory Test } \\
\text { Biochemical/ } \\
\text { Biological Assays }\end{array}$} & \multirow{2}{*}{$\begin{array}{c}\text { Other } \\
\text { Biological Analysis }\end{array}$} & \multirow{2}{*}{ REF } \\
\hline & Ex Vivo Study & Clinical Trial & $\begin{array}{l}\text { Chemical } \\
\text { Assays }\end{array}$ & $\begin{array}{c}\text { Biochemical/ } \\
\text { Cellular Assays }\end{array}$ & & & \\
\hline $\begin{array}{c}\text { Sustained consumption of HPC/MPC/LPC VOO } \\
\text { on healthy } \\
\text { subjects following a randomized, } \\
\text { crossover, controlled trial } \\
\end{array}$ & & $\begin{array}{l}\text { Plasma, } \\
\text { serum and urine }\end{array}$ & $\begin{array}{l}\text { Total F2 } \alpha \text {-isoprostanes, } \\
\text { C18 hydroxy fatty acids, T } \\
\text { and HT }\end{array}$ & $\begin{array}{l}\text { Oxidative damage, } \\
\text { endogenous and } \\
\text { exogenous } \\
\text { antioxidants }\end{array}$ & & $\begin{array}{l}\text { Glucose, total cholesterol, } \\
\text { HDL-C, LDL-C and TAG }\end{array}$ & [15] \\
\hline $\begin{array}{c}\text { Sustained consumption of EVOO vs. ROO in healthy } \\
\text { subjects following a } \\
\text { randomized, crossover trial }\end{array}$ & & & & OxLDL & & $\begin{array}{l}\text { Glucose, total cholesterol, } \\
\text { HDL-C, LDL-C, TAG and } \\
\text { extensive study on HDL }\end{array}$ & [25] \\
\hline $\begin{array}{c}\text { Post prandial consumption of HPC vs. LPC VOO in } \\
\text { hypercholesterolemic } \\
\text { subjects }\end{array}$ & & $\begin{array}{l}\text { Plasma and } \\
\text { serum }\end{array}$ & & $\begin{array}{l}\text { 8-epi- } F_{2 \alpha}, \text { LPO } \\
\text { and NO(x) }\end{array}$ & & $\begin{array}{l}\text { Ischemic Reactive } \\
\text { Hyperemia and lipid } \\
\text { parameters }\end{array}$ & [26] \\
\hline $\begin{array}{l}\text { Sustained consumption of EVOO in healthy elderly } \\
\text { subjects following a } \\
\text { randomized trial }\end{array}$ & & $\begin{array}{l}\text { Plasma and } \\
\text { erythrocyte }\end{array}$ & TAC, OH-Tyr & CAT, SOD, GSH-px & & $\begin{array}{l}\text { Glucose, total cholesterol, } \\
\text { HDL-C, LDL-C and TAG }\end{array}$ & [29] \\
\hline EVOO vs. ROO & $\begin{array}{c}\begin{array}{c}\text { Plasma from } \\
\text { healthy subjects }\end{array} \\
\end{array}$ & & & $\begin{array}{c}\text { Copper sulfate-oxidized } \\
\text { LDL/TBARS }\end{array}$ & & & [30] \\
\hline $\begin{array}{l}\text { Post prandial administration of EVOO produced } \\
\text { from the Picual variety of O. europea L. fruit in } \\
\text { healthy subjects }\end{array}$ & & Plasma & & $\begin{array}{l}\text { Analysis of T and HT } \\
\text { metabolites ability to bind the } \\
\text { human LDL }\end{array}$ & & & [31] \\
\hline $\begin{array}{c}\text { Sustained consumption of HPC/MPC/LPC VOO } \\
\text { on healthy } \\
\text { subjects following a randomized, } \\
\text { crossover, controlled trial }\end{array}$ & & $\begin{array}{l}\text { Plasma, } \\
\text { serum and urine }\end{array}$ & $\begin{array}{l}\text { C18 hydroxy fatty acids } \\
\text { and LDL } \\
\text { cholesterol-uninduced } \\
\text { conjugated dienes }\end{array}$ & $\begin{array}{l}\text { Analysis of LD } \\
\text { oxidation }\end{array}$ & & $\begin{array}{l}\text { Total Cholesterol, HDL-C } \\
\text { and LDL-C }\end{array}$ & [32] \\
\hline $\begin{array}{l}\text { Sustained consumption of refined, } \\
\text { common and virgin olive oil in healthy subjects } \\
\text { following a placebo-controlled, double blind, } \\
\text { cross-over, randomized, trial }\end{array}$ & & $\begin{array}{l}\text { Plasma, } \\
\text { serum and urine }\end{array}$ & HT and T & $\begin{array}{l}\text { Analysis of LD } \\
\text { oxidation, LDL } \\
\text { resistance } \\
\text { to oxidation }\end{array}$ & & $\begin{array}{l}\text { Glucose, total Cholesterol, } \\
\text { HDL-C and LDL-C }\end{array}$ & [19] \\
\hline $\begin{array}{l}\text { Short-term consumption of HPC/MPC/LPC EVOO } \\
\text { on healthy } \\
\text { subjects following a double-blind, } \\
\text { randomized, crossover trial }\end{array}$ & & $\begin{array}{l}\text { Plasma, } \\
\text { serum and urine }\end{array}$ & $\begin{array}{l}\text { 8-oxo-dG, MDA, } \\
\text { 8-iso-PGF2 } \alpha, \mathrm{T}, \mathrm{HT} \\
\quad \text { and MHT }\end{array}$ & OxLDL, GR and GSH-Px & & $\begin{array}{l}\text { Total Cholesterol, HDL-C } \\
\text { and LDL-C }\end{array}$ & [20] \\
\hline
\end{tabular}


Table 1. Cont.

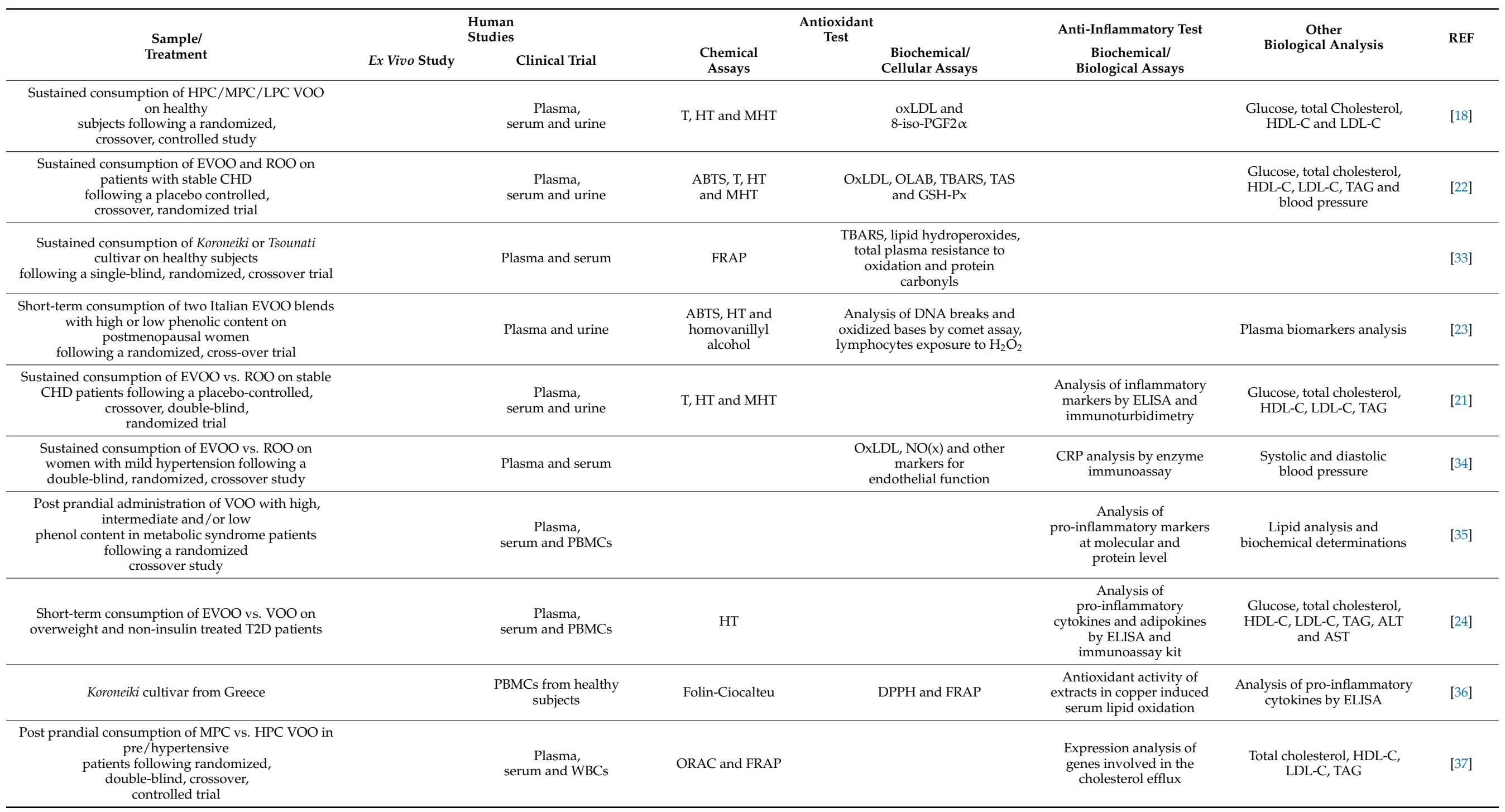


Regarding the studies in which an accurate chemical characterization of VOO polyphenols was related to their antioxidant ability tested not only by biochemical but also by cellular assays, different clinical trials were reported (Table 1). Specifically, a sustained consumption of VOO $(161 \mathrm{mg} / \mathrm{kg})$ vs. refined OO $(14.7 \mathrm{mg} / \mathrm{kg})$ was examined in stable coronary heart disease (CHD) patients with a diagnosis of hypertension [22]. In fact, the present study aimed to evaluate the impact of phenolic compounds not only on oxidative stress in stable CHD patients, but also on blood pressure in hypertensive and stable CHD patients. The authors demonstrated that VOO decreased oxLDL and increased GSH-Px, as compared to refined OO. This effect on the enzymes regulating the antioxidant status was also observed in elderly healthy subjects. The consumption of EVOO induced an enhancement of the endogen antioxidant system in healthy elderly people, in which an increased oxidative stress and an impaired antioxidant defense system were usually reported [29]. Moreover, the increased intake of phenolic compounds was also able to decrease the systolic blood pressure. However, only few human studies analyzed the positive effects of OO on blood pressure [39]; this could possibly be the reason why the EFSA could not draw a scientific substantiation for the relative claimed effect [16].

It is important to report also contrasting results obtained from a single-blind, randomized, crossover trial on Greek smokers undergoing a sustained consumption of two EVOO cultivars characterized by a HPC and a LPC. In fact, no differences were reported for total plasma resistance to oxidation, the ferric reducing ability of plasma, the concentrations of protein carbonyl, MDA, or lipid hydroperoxides [33]. This could be due to the relatively small size of the trial, and to its organization requiring a run-in period before the first treatment period and a washout between the two treatment periods. Due to a missed control for other fat sources than olives and oil-containing products, it was not possible to establish the effectivity in these periods. Finally, another clinical trial demonstrated the antioxidant ability of phenolic compound enriched EVOO to protect healthy postmenopausal women from oxidative DNA damage, as assessed by the comet assay in peripheral blood lymphocytes [23].

\section{Correlation among EVOO Polyphenols Chemical Characterization, Anti-Inflammatory Potential and Biological Activities in Human Studies}

The anti-inflammatory effect of VOO's phenolic content was demonstrated in many pathological contexts such as CVD, chronic inflammatory disorders, such as the intestinal inflammation leading to colorectal cancer (CRC) development, and autoimmune diseases [2]. A clinical trial on stable CHD patients demonstrated the ability of VOO to reduce two proinflammatory markers, i.e., Interleukin 6 (IL-6) and C-Reactive Protein (CRP), as compared to refined olive oil (ROO), devoid of phenolic compounds [21].

Another study on women with mild hypertension, in which both the anti-inflammatory and antioxidant VOO properties were analyzed, demonstrated the ability of polyphenols enriched VOO to decrease the blood pressure and inflammatory markers, and improve the endothelial function, thus supporting a beneficial role for VOO polyphenols in CHD prevention [34].

Differences in the total polyphenols content, measured by the Folin-Ciocalteu method, was useful to understand the results of a human study based on VOO post prandial administration in patients affected by a metabolic syndrome. Specifically, the anti-inflammatory potential of VOO samples correlates with its polyphenols content. Thus, VOO with low polyphenol content was able to increase the postprandial release of endotoxin LPS (lipopolysaccharides) and its target genes like TLR4 (Toll Like Receptor 4) that, in turn, activates NF- $\mathrm{B}$ B signaling, promoting the secretion of pro-inflammatory cytokines and chemokines by PBMCs (peripheral blood mononuclear cells) like IL-1 $\beta$ and CXCL1 (chemokine C-X-C motif Ligand 1) at molecular level, as well as IL-6, whose significant up-modulation was found also in plasma samples [35].

Moreover, the high polyphenol content in EVOO, as measured by HPLC, is able to ameliorate the T2D patients' metabolism. In fact, apart from the induction of an improve- 
ment in anthropometric measurements, EVOO enriched in phenolic content is also able to modulate some biochemical parameters, such as the fasting glucose and liver enzymes, along with inflammatory adipokines profile, in particular visfatin [24].

Furthermore, differences in phenolic content, measured by the Folin-Ciocalteux method, were also related to another important aspect of $\mathrm{OO}$ research, i.e., the maturation process in an ex vivo study on PBMCs from healthy subjects treated with Koroneiki cultivar (Greece). Specifically, the increase in phenolic compounds during maturation correlated with an increase in antioxidant and anti-inflammatory properties of the tested cultivar, as reported by results from DPPH, FRAP and copper-induced lipid oxidation tests, and by the decrement of some circulating pro-inflammatory cytokines (TNF- $\alpha$ and MCP-1) levels [36]. Moreover, the correlation of VOO phenolic content, identified by HPLC, and antioxidant activity, measured by ORAC assay, was investigated as related to the nutrigenomic effect in a clinical trial on pre/hypertensive patients, as discussed in a recent review [3]. Post prandial administration of VOO with HPC promoted several atheroprotective molecular mechanisms acting on genes related to cholesterol efflux in humans, as compared to VOO with an MPC. Among these genes, the increase in ABCA1 (one of the main transmembrane transporters for cholesterol efflux), PPAR- $\alpha$ (peroxisome proliferator-activated receptor-alpha) and PPAR- $\gamma$ transcription factors controlling both lipid metabolism and inflammation, correlated with a decrease in oxidized LDL. Furthermore, ORAC values were directly correlated with the molecular induction of PPAR genes and their coactivator PPARBP (PPAR-binding protein). This could explain the increase in CD36 molecular expression found after HPC vs. LPC treatment in human white blood cells. In fact, CD36 is a scavenger receptor promoting the uptake of oxidized LDL. Finally, the enrichment of polyphenols in VOO induced, in these patients, the up-modulation of other transmembrane transporters for cholesterol efflux, i.e., SR-B1 [37].

Notwithstanding the reported studies analyzing the anti-inflammatory activity of VOO phenolic compounds (Table 1), a specific Health Claim was not released by the EFSA. In fact, even if a claimed effect on anti-inflammatory properties of olive biophenols exists in the context of diseases such as osteoarthritis or rheumatoid arthritis, the EFSA define it as general and not specific, also because it does not comply with the criteria laid down in Regulation (EC) No 1924/2006 [16].

An important consideration emerging from this paragraph is that studies correlating the chemical characterization and the anti-inflammatory properties of VOO phenolic compounds are still scanty. In fact, even if these techniques were used for other tested compounds from different plants [40-45], they did not find their application in VOO research until now. Thus, more research is needed to extend the use of chemical tests for the study of VOO anti-inflammatory properties.

\section{Conclusions}

Considering the properties of EVOO as a functional food reported in this review, the process by which studies demonstrating VOO's beneficial effects on human health can be translated into an approved Health Claim appears long, complex and requires a tight correlation between the chemical characterization of VOO's beneficial compounds and their specific dose to be used in a defined physio-pathological context. A specific indication for the dosage is extremely important to avoid a shift toward pro-inflammatory and pro-oxidant activities typically associated with a high polyphenol intake [46]. Starting from the studies discussed in this review and summarized in Table 1, the urgent need of a systematic approach to study VOO's beneficial properties comes up clearly. In fact, all the studies that analyzed VOO's beneficial properties only by a unique approach (in vitro or in vivo, or ex vivo or human studies) and important aspects relative to the tested compounds (E/VOO vs. its by-products), the $\mathrm{OO}$ dose, $\mathrm{OO}$ maturation process, as well as geographical/climatic conditions, were often underestimated [47]. Moreover, many are the studies in which VOO is directly tested on humans, neglecting important data relative to the bioavailability. Additionally, some discrepancies for the reported results 
in human studies could be explained by different administration timings (short-term vs. sustained consumption). The application of different techniques also complicates the comparison of the results obtained from distinct studies. In fact, the use of chemical and/or biochemical/biological assays gives back specific scientific answers, and each assay is characterized by different features in terms of sensibility and specificity. For this reason, a correct choice of the assays to be used in each study is crucial. Thus, like the strict iter followed for drug discoveries and validation, a well-structured protocol to study functional foods is needed in which food compounds have to be chemically characterized first, and then sequentially tested by in vitro, in vivo/ex vivo assays, and finally on humans (Figure 1).

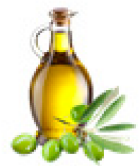

\section{Chemical characterization}<smiles>O=C(O)Cc1cccc(O)c1</smiles><smiles>C=CC=C</smiles>

In vitro study

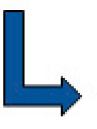

In vivo/ex vivo study
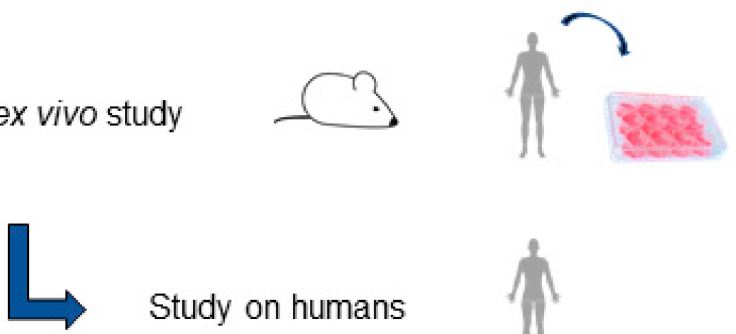

Study on humans

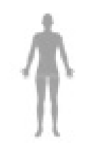

Figure 1. Systematic approach to study the EVOO beneficial activity on human health.

Even if utopistic until now, this new systematic approach could be very useful to overcome one of the main drawbacks of the clinical trials, i.e., the lack of correlation with the results obtained in preliminary studies.

Finally, the need to extend the use of chemical assays to test the anti-inflammatory properties of VOO implies an important consideration. Once the results of these assays are validated by biological studies, one possible application could be the creation of specific devices able to simply discriminate functional foods from foods without beneficial effects on human health. These devices could have the typical advantages of chemical assays, i.e., saving time and costs, and their use could be especially important for OO producers, helping them to better manage $\mathrm{OO}$ production, with a good economic relapse on the market.

Author Contributions: Conceptualization: F.C., M.L.C. and S.D.S.; Writing-original draft preparation, S.D.S.; writing-review and editing, F.C. and M.L.C.; funding acquisition, F.C. and M.L.C. All authors have read and agreed to the published version of the manuscript.

Funding: EU project-OLIVE-SOUND-Ultrasound reactor-The solution for a continuous olive oil extraction process H2020-EU.2.1-INDUSTRIAL LEADERSHIP-EIC-FTI-2018-2020-Fast Track to Innovation (FTI)-European Union's Horizon 2020 research and innovation program under grant agreement No. 820587. The AGER 2 Project, grant n. 2016-0174, AGER Foundation-Olive Tree and Oil: Competitive-Claims of olive oil to improve the market value of the product. Stefania De Santis is funded by PON Ricerca e Innovazione 2014-2020: Progetto AIM1801289-attività 3-linea 1.

Conflicts of Interest: The authors declare no conflict of interest. 


\section{References}

1. Bucciantini, M.; Leri, M.; Nardiello, P.; Casamenti, F.; Stefani, M. Olive Polyphenols: Antioxidant and Anti-Inflammatory Properties. Antioxidants 2021, 10, 1044. [CrossRef]

2. Visioli, F.; Franco, M.; Toledo, E.; Luchsinger, J.; Willett, W.C.; Hu, F.B.; Martinez-Gonzalez, M.A. Olive oil and prevention of chronic diseases: Summary of an International conference. Nutr. Metab. Cardiovasc. Dis. 2018, 28, 649-656. [CrossRef]

3. De Santis, S.; Cariello, M.; Piccinin, E.; Sabba, C.; Moschetta, A. Extra Virgin Olive Oil: Lesson from Nutrigenomics. Nutrients 2019, 11, 2085. [CrossRef]

4. $\quad$ De Santis, S.; Liso, M.; Verna, G.; Curci, F.; Milani, G.; Faienza, M.F.; Franchini, C.; Moschetta, A.; Chieppa, M.; Clodoveo, M.L.; et al. Extra Virgin Olive Oil Extracts Modulate the Inflammatory Ability of Murine Dendritic Cells Based on Their Polyphenols Pattern: Correlation between Chemical Composition and Biological Function. Antioxidants 2021, 10, 1076. [CrossRef]

5. De Luca, M.; Restuccia, D.; Clodoveo, M.L.; Puoci, F.; Ragno, G. Chemometric analysis for discrimination of extra virgin olive oils from whole and stoned olive pastes. Food Chem. 2016, 202, 432-437. [CrossRef]

6. Roselli, L.; Cicia, G.; Cavallo, C.; Del Giudice, T.; Carlucci, D.; Clodoveo, M.L.; De Gennaro, B.C. Consumers' willingness to buy innovative traditional food products: The case of extra-virgin olive oil extracted by ultrasound. Food Res. Int. 2018, 108, 482-490. [CrossRef]

7. Amirante, P.; Clodoveo, M.L.; Leone, A.; Tamborrino, A.; Patel, V.B. Influence of Different Centrifugal Extraction Systems on Antioxidant Content and Stability of Virgin Olive Oil. In Olives and Olive Oil in Health and Disease Prevention; Academic Press: Cambridge, MA, USA, 2010; pp. 85-93.

8. Amirante, P.; Clodoveo, M.L.; Tamborrino, A.; Leone, A.; Paice, A.G. Influence of the crushing system: Phenol content in virgin olive oil produced from whole and de-stoned pastes. In Olives and Olive Oil in Health and Disease Prevention; Academic Press: Cambridge, MA, USA, 2010; pp. 69-76.

9. Santangelo, C.; Vari, R.; Scazzocchio, B.; De Sanctis, P.; Giovannini, C.; D'Archivio, M.; Masella, R. Anti-inflammatory Activity of Extra Virgin Olive Oil Polyphenols: Which Role in the Prevention and Treatment of Immune-Mediated Inflammatory Diseases? Endocr. Metab. Immune Disord. Drug Targets 2018, 18, 36-50. [CrossRef]

10. Cariello, M.; Contursi, A.; Gadaleta, R.M.; Piccinin, E.; De Santis, S.; Piglionica, M.; Spaziante, A.F.; Sabba, C.; Villani, G.; Moschetta, A. Extra-Virgin Olive Oil from Apulian Cultivars and Intestinal Inflammation. Nutrients 2020, 12, 1084. [CrossRef]

11. Emma, M.R.; Augello, G.; Di Stefano, V.; Azzolina, A.; Giannitrapani, L.; Montalto, G.; Cervello, M.; Cusimano, A. Potential Uses of Olive Oil Secoiridoids for the Prevention and Treatment of Cancer: A Narrative Review of Preclinical Studies. Int. J. Mol. Sci. 2021, 22, 1234. [CrossRef]

12. Bongiorno, D.; Di Stefano, V.; Indelicato, S.; Avellone, G.; Ceraulo, L. Bio-phenols determination in olive oils: Recent mass spectrometry approaches. Mass Spectrom. Rev. 2021, e21744. [CrossRef]

13. Olmo-Cunillera, A.; Lopez-Yerena, A.; Lozano-Castellon, J.; Tresserra-Rimbau, A.; Vallverdu-Queralt, A.; Perez, M. NMR spectroscopy: A powerful tool for the analysis of polyphenols in extra virgin olive oil. J. Sci. Food Agric. 2020, 100, 1842-1851. [CrossRef]

14. Carluccio, M.A.; Martinelli, R.; Massaro, M.; Calabriso, N.; Scoditti, E.; Maffia, M.; Verri, T.; Gatta, V.; De Caterina, R. Nutrigenomic Effect of Hydroxytyrosol in Vascular Endothelial Cells: A Transcriptomic Profile Analysis. Nutrients 2021, 13, 3990. [CrossRef]

15. Covas, M.I.; Nyyssonen, K.; Poulsen, H.E.; Kaikkonen, J.; Zunft, H.J.; Kiesewetter, H.; Gaddi, A.; de la Torre, R.; Mursu, J.; Baumler, H.; et al. The effect of polyphenols in olive oil on heart disease risk factors: A randomized trial. Ann. Intern. Med. 2006, 145, 333-341. [CrossRef]

16. EFSA. Scientific Opinion on the substantiation of health claims related to polyphenols in olive and protection of LDL particles from oxidative damage (ID 1333, 1638, 1639, 1696, 2865), maintenance of normal blood HDL-cholesterol concentrations (ID 1639), maintenance of normal blood pressure (ID 3781), "anti-inflammatory properties" (ID 1882), "contributes to the upper respiratory tract health" (ID 3468), "can help to maintain a normal function of gastrointestinal tract" (3779), and "contributes to body defences against external agents" (ID 3467) pursuant to Article 13(1) of Regulation (EC) No 1924/200. EFSA J. 2011, 9, 2033.

17. The European Commission. Establishing a List of Permitted Health Claims Made on Foods, Other than Those Referring to the Reduction of Disease Risk and to Children's Development and Health; The European Commission: Luxembourg, 2012.

18. Covas, M.I.; de la Torre, K.; Farre-Albaladejo, M.; Kaikkonen, J.; Fito, M.; Lopez-Sabater, C.; Pujadas-Bastardes, M.A.; Joglar, J.; Weinbrenner, T.; Lamuela-Raventos, R.M.; et al. Postprandial LDL phenolic content and LDL oxidation are modulated by olive oil phenolic compounds in humans. Free Radic. Biol. Med. 2006, 40, 608-616. [CrossRef]

19. Marrugat, J.; Covas, M.I.; Fito, M.; Schroder, H.; Miro-Casas, E.; Gimeno, E.; Lopez-Sabater, M.C.; de la Torre, R.; Farre, M.; Investigators, S. Effects of differing phenolic content in dietary olive oils on lipids and LDL oxidation-A randomized controlled trial. Eur. J. Nutr. 2004, 43, 140-147. [CrossRef]

20. Weinbrenner, T.; Fito, M.; de la Torre, R.; Saez, G.T.; Rijken, P.; Tormos, C.; Coolen, S.; Albaladejo, M.F.; Abanades, S.; Schroder, H.; et al. Olive oils high in phenolic compounds modulate oxidative/antioxidative status in men. J. Nutr. 2004, 134, 2314-2321. [CrossRef]

21. Fito, M.; Cladellas, M.; de la Torre, R.; Marti, J.; Munoz, D.; Schroder, H.; Alcantara, M.; Pujadas-Bastardes, M.; Marrugat, J.; Lopez-Sabater, M.C.; et al. Anti-inflammatory effect of virgin olive oil in stable coronary disease patients: A randomized, crossover, controlled trial. Eur. J. Clin. Nutr. 2008, 62, 570-574. [CrossRef] 
22. Fito, M.; Cladellas, M.; de la Torre, R.; Marti, J.; Alcantara, M.; Pujadas-Bastardes, M.; Marrugat, J.; Bruguera, J.; Lopez-Sabater, M.C.; Vila, J.; et al. Antioxidant effect of virgin olive oil in patients with stable coronary heart disease: A randomized, crossover, controlled, clinical trial. Atherosclerosis 2005, 181, 149-158. [CrossRef]

23. Salvini, S.; Sera, F.; Caruso, D.; Giovannelli, L.; Visioli, F.; Saieva, C.; Masala, G.; Ceroti, M.; Giovacchini, V.; Pitozzi, V.; et al. Daily consumption of a high-phenol extra-virgin olive oil reduces oxidative DNA damage in postmenopausal women. Br. J. Nutr. 2006, 95, 742-751. [CrossRef]

24. Santangelo, C.; Filesi, C.; Vari, R.; Scazzocchio, B.; Filardi, T.; Fogliano, V.; D’Archivio, M.; Giovannini, C.; Lenzi, A.; Morano, S.; et al. Consumption of extra-virgin olive oil rich in phenolic compounds improves metabolic control in patients with type 2 diabetes mellitus: A possible involvement of reduced levels of circulating visfatin. J. Endocrinol. Investig. 2016, 39, 1295-1301. [CrossRef]

25. Hernaez, A.; Fernandez-Castillejo, S.; Farras, M.; Catalan, U.; Subirana, I.; Montes, R.; Sola, R.; Munoz-Aguayo, D.; GelabertGorgues, A.; Diaz-Gil, O.; et al. Olive oil polyphenols enhance high-density lipoprotein function in humans: A randomized controlled trial. Arter. Thromb. Vasc. Biol. 2014, 34, 2115-2119. [CrossRef]

26. Ruano, J.; Lopez-Miranda, J.; Fuentes, F.; Moreno, J.A.; Bellido, C.; Perez-Martinez, P.; Lozano, A.; Gomez, P.; Jimenez, Y.; Perez Jimenez, F. Phenolic content of virgin olive oil improves ischemic reactive hyperemia in hypercholesterolemic patients. J. Am. Coll. Cardiol. 2005, 46, 1864-1868. [CrossRef]

27. Widmer, R.J.; Freund, M.A.; Flammer, A.J.; Sexton, J.; Lennon, R.; Romani, A.; Mulinacci, N.; Vinceri, F.F.; Lerman, L.O.; Lerman, A. Beneficial effects of polyphenol-rich olive oil in patients with early atherosclerosis. Eur. J. Nutr. 2013, 52, 1223-1231. [CrossRef]

28. Flori, L.; Donnini, S.; Calderone, V.; Zinnai, A.; Taglieri, I.; Venturi, F.; Testai, L. The Nutraceutical Value of Olive Oil and Its Bioactive Constituents on the Cardiovascular System. Focusing on Main Strategies to Slow Down Its Quality Decay during Production and Storage. Nutrients 2019, 11, 1962.

29. Oliveras-Lopez, M.J.; Molina, J.J.; Mir, M.V.; Rey, E.F.; Martin, F.; de la Serrana, H.L. Extra virgin olive oil (EVOO) consumption and antioxidant status in healthy institutionalized elderly humans. Arch. Gerontol. Geriatr. 2013, 57, 234-242. [CrossRef]

30. Fito, M.; Covas, M.I.; Lamuela-Raventos, R.M.; Vila, J.; Torrents, L.; de la Torre, C.; Marrugat, J. Protective effect of olive oil and its phenolic compounds against low density lipoprotein oxidation. Lipids 2000, 35, 633-638. [CrossRef]

31. de la Torre-Carbot, K.; Chavez-Servin, J.L.; Jauregui, O.; Castellote, A.I.; Lamuela-Raventos, R.M.; Fito, M.; Covas, M.I.; MunozAguayo, D.; Lopez-Sabater, M.C. Presence of virgin olive oil phenolic metabolites in human low density lipoprotein fraction: Determination by high-performance liquid chromatography-electrospray ionization tandem mass spectrometry. Anal. Chim. Acta 2007, 583, 402-410. [CrossRef]

32. de la Torre-Carbot, K.; Chavez-Servin, J.L.; Jauregui, O.; Castellote, A.I.; Lamuela-Raventos, R.M.; Nurmi, T.; Poulsen, H.E.; Gaddi, A.V.; Kaikkonen, J.; Zunft, H.F.; et al. Elevated circulating LDL phenol levels in men who consumed virgin rather than refined olive oil are associated with less oxidation of plasma LDL. J. Nutr. 2010, 140, 501-508. [CrossRef]

33. Moschandreas, J.; Vissers, M.N.; Wiseman, S.; van Putte, K.P.; Kafatos, A. Extra virgin olive oil phenols and markers of oxidation in Greek smokers: A randomized cross-over study. Eur. J. Clin. Nutr. 2002, 56, 1024-1029. [CrossRef]

34. Moreno-Luna, R.; Munoz-Hernandez, R.; Miranda, M.L.; Costa, A.F.; Jimenez-Jimenez, L.; Vallejo-Vaz, A.J.; Muriana, F.J.; Villar, J.; Stiefel, P. Olive oil polyphenols decrease blood pressure and improve endothelial function in young women with mild hypertension. Am. J. Hypertens 2012, 25, 1299-1304. [CrossRef]

35. Camargo, A.; Rangel-Zuniga, O.A.; Haro, C.; Meza-Miranda, E.R.; Pena-Orihuela, P.; Meneses, M.E.; Marin, C.; Yubero-Serrano, E.M.; Perez-Martinez, P.; Delgado-Lista, J.; et al. Olive oil phenolic compounds decrease the postprandial inflammatory response by reducing postprandial plasma lipopolysaccharide levels. Food Chem. 2014, 162, 161-171. [CrossRef]

36. Kaliora, A.C.; Artemiou, A.; Giogios, I.; Kalogeropoulos, N. The impact of fruit maturation on bioactive microconstituents, inhibition of serum oxidation and inflammatory markers in stimulated PBMCs and sensory characteristics of Koroneiki virgin olive oils from Messenia, Greece. Food Funct. 2013, 4, 1185-1194. [CrossRef]

37. Farras, M.; Valls, R.M.; Fernandez-Castillejo, S.; Giralt, M.; Sola, R.; Subirana, I.; Motilva, M.J.; Konstantinidou, V.; Covas, M.I.; Fito, M. Olive oil polyphenols enhance the expression of cholesterol efflux related genes in vivo in humans. A randomized controlled trial. J. Nutr. Biochem. 2013, 24, 1334-1339. [CrossRef]

38. Estruch, R.; Ros, E.; Salas-Salvado, J.; Covas, M.I.; Corella, D.; Aros, F.; Gomez-Gracia, E.; Ruiz-Gutierrez, V.; Fiol, M.; Lapetra, J.; et al. Primary Prevention of Cardiovascular Disease with a Mediterranean Diet Supplemented with Extra-Virgin Olive Oil or Nuts. N. Engl. J. Med. 2018, 378, e34. [CrossRef]

39. Ferrara, L.A.; Raimondi, A.S.; d'Episcopo, L.; Guida, L.; Dello Russo, A.; Marotta, T. Olive oil and reduced need for antihypertensive medications. Arch. Intern. Med. 2000, 160, 837-842. [CrossRef]

40. Yesmin, S.; Paul, A.; Naz, T.; Rahman, A.B.M.A.; Akhter, S.F.; Wahed, M.I.I.; Emran, T.B.; Siddiqui, S.A. Membrane stabilization as a mechanism of the anti-inflammatory activity of ethanolic root extract of Choi (Piper chaba). Clin. Phytosci. 2020, 6, 59. [CrossRef]

41. Parvin, M.S.; Das, N.; Jahan, N.; Akhter, M.A.; Nahar, L.; Islam, M.E. Evaluation of in vitro anti-inflammatory and antibacterial potential of Crescentia cujete leaves and stem bark. BMC Res. Notes 2015, 8, 412. [CrossRef]

42. Bag, A.; Kumar Bhattacharyya, S.; Kumar Pal, N.; Ranjan Chattopadhyay, R. Anti-inflammatory, anti-lipid peroxidative, antioxidant and membrane stabilizing activities of hydroalcoholic extract of Terminalia chebula fruits. Pharm. Biol. 2013, 51, 1515-1520. [CrossRef] 
43. Gunathilake, K.; Ranaweera, K.; Rupasinghe, H.P.V. In Vitro Anti-Inflammatory Properties of Selected Green Leafy Vegetables. Biomedicines 2018, 6, 107. [CrossRef]

44. Kedi, P.B.E.; Meva, F.E.; Kotsedi, L.; Nguemfo, E.L.; Zangueu, C.B.; Ntoumba, A.A.; Mohamed, H.E.A.; Dongmo, A.B.; Maaza, M. Eco-friendly synthesis, characterization, in vitro and in vivo anti-inflammatory activity of silver nanoparticle-mediated Selaginella myosurus aqueous extract. Int. J. Nanomed. 2018, 13, 8537-8548. [CrossRef]

45. Kumari, C.; Yasmin, N.; Hussain, M.R.; Babuselvam, M. Invitro Anti-Inflammatory and Anti-Arthritic Property of Rhizopora Mucronata Leaves. Int. J. Pharma Sci. Res. 2015, 6, 482-485.

46. Visioli, F.; Davalos, A.; Lopez de Las Hazas, M.C.; Crespo, M.C.; Tome-Carneiro, J. An overview of the pharmacology of olive oil and its active ingredients. Br. J. Pharmacol. 2020, 177, 1316-1330. [CrossRef]

47. De Santis, S.; Clodoveo, M.L.; Cariello, M.; D'Amato, G.; Franchini, C.; Faienza, M.F.; Corbo, F. Polyphenols and obesity prevention: Critical insights on molecular regulation, bioavailability and dose in preclinical and clinical settings. Crit. Rev. Food Sci. Nutr. 2020, 61, 1804-1826. 